\title{
Disputas mineras en Chile y su caracterización como potenciales arbitrajes internacionales
}

\author{
Álvaro Awad Sirhan* \\ Recibido/Received: 08/07/2021 \\ Aceptado/Accepted: 11/10/2021
}

\begin{abstract}
Sumario: 1. Los riesgos de la actividad minera. 2. Minería y arbitraje. 3. El arbitraje de minería en América Latina. 4. La solución de disputas mineras en Chile. 4.1. Chile: un país minero. 4.2. Disputas domésticas. 4.3. Disputas internacionales. 4.4. El proceso constituyente en curso. 4.5. Un contraste con América Latina. 5. Conclusiones.
\end{abstract}

Resumen: La industria minera presenta riesgos y peculiaridades que la distinguen de otros sectores económicos propensos a la controversia. El sistema arbitral ofrece ventajas para la solución de disputas en la materia. El arbitraje de minería empieza a convertirse en un área de práctica especializada. Si bien a nivel global algunos expertos sugieren la existencia de una lex mineralia, cada región tiene sus desafíos propios. En América Latina los conflictos sociales y ambientales destacan como fuente de conflictos, y suelen dar lugar a arbitrajes de inversión. En el caso de Chile, las disputas mineras que no pueden resolverse localmente presentan potencial para canalizarse por la vía de arbitrajes internacionales comerciales o de inversión. La escasa experiencia chilena en esta última categoría de procesos contrasta dramáticamente con las tendencias globales y la mayor incidencia de controversias mineras de alcance internacional. ¿Es Chile realmente tan distinto a los demás países de la región?

Palabras Clave: Arbitraje de minería, Chile, América Latina.

* Socio de Contreras Velozo. Profesor de Derecho Civil, Arbitraje y Litigación Oral de la Pontificia Universidad Católica de Chile. Abogado summa cum laude de la Pontificia Universidad Católica de Chile y Master en Derecho por la Universidad de Chicago. 


\title{
Mining disputes in Chile and their characterization as potential International Arbitration procedures
}

\begin{abstract}
Aвstract: The mining industry has risks and peculiarities that distinguish it from other economic sectors prone to controversy. Arbitration provides advantages for the resolution of such industryspecific disputes. Mining arbitration is beginning to evolve into a specialized practice area. Although at a global level some experts suggest the existence of a lex mineralia, each region has its own distinct challenges. In Latin America, social and environmental conflicts stand out as an important source of disputes, and usually lead to investment arbitrations. In the case of Chile, mining disputes that cannot be resolved locally may ultimately be adjudicated via international commercial or investment arbitrations. The dearth of national experience in the latter category of proceedings dramatically contrasts with the global trends as well as with an increased incidence of mining disputes with an international reach. Is Chile so different from other countries in the region?
\end{abstract}

Keywords: Mining Arbitration, Chile, Latin America.

\section{LOS RIESGOS DE LA ACTIVIDAD MINERA}

La minería es una industria proclive al riesgo, y el riesgo verificado suele convertirse en conflicto cuando no ha sido bien distribuido. Según veremos, los riesgos en la actividad minera pueden ser intrínsecos al proyecto - piénsese, por ejemplo, en el riesgo propio de la exploración que no llega al resultado esperado- o bien extrínsecos - como el riesgo de conflictuar con una comunidad local cercana al yacimiento. Del mismo modo, los riesgos aparecen en las distintas etapas del proyecto minero, desde el diseño de la inversión hasta la comercialización del producto.

Por un lado, nótese desde luego que el emprendimiento minero depende fuertemente de la cooperación de parte del Estado en que tiene lugar. Esta colaboración debe mantenerse por largos períodos de tiempo. Como es obvio, hay en ello un evidente riesgo político, bajo 
el cual la inversión de una empresa minera puede verse afectada por nacionalizaciones, expropiaciones o regulaciones cambiantes ${ }^{1}$.

Se trata de una industria con una participación importante de entidades públicas. En efecto, habitualmente es el Estado quien entrega en concesión o licencia el derecho de explorar o explotar el mineral. Al tratarse de proyectos de largo plazo, altamente sensibles al cambio político y regulatorio, la interferencia estatal a lo largo de un proyecto puede ser fatal para la viabilidad económica del mismo.

La necesidad de metales y minerales ha incentivado la inversión extranjera directa, con una presencia significativa en países en vías de desarrollo. En tal sentido, y en lo que refiere a la situación de la industria minera en la actualidad, debe considerarse que minerales y metales como el cobre, el cobalto, el litio, el silicio, el zinc y el níquel, entre otros, juegan un rol fundamental en el crecimiento de la energía limpia y la tecnología ${ }^{2}$. Mientras el cobre se utiliza para la conducción de electricidad, el cobalto, el litio, el zinc y el níquel se aplican en la fabricación de baterías de automóviles eléctricos y dispositivos electrónicos portátiles. Por su parte, el silicio se usa en paneles solares ${ }^{3}$.

Como puede suponerse, los proyectos mineros exigen una inversión inicial sustantiva, que solo es recuperada luego de un período extenso. En razón de ello, los conflictos mineros usualmente involucran cuantías muy relevantes. ${ }^{4}$ Es el riesgo de la inversión. Muchas veces los Estados son presionados a actuar en contra de un proyecto minero en atención a la situación ambiental, social o de derechos humanos vinculada al mismo. Es el riesgo social ${ }^{5}$.

1. Los inversionistas extranjeros suelen revisar la historia del país antes de decidir si invertir o no. En caso que un inversionista resuelva invertir en un país que tiende a la expropiación, asume un riesgo mayor.

2. J. Fry y L. Bret (Eds.). The Guide to Mining Arbitrations, Law Business Research, 2019, p. iii.

3. Ídem, p. 2.

4. Para graficar en extremo este punto, véase el arbitraje de inversión iniciado por Tethyan Copper Company c. la República Islámica de Pakistán, en que el tribunal dictó un laudo condenando a esta última al pago de aproximadamente 5.800 millones de dólares, por el rechazo de la licencia minera para explotar oro y cobre en el proyecto Reko Diq, ubicado en la provincia de Balochistán (Tethyan Copper Company Pty Limited c. República Islámica de Pakistán, Caso CIADI $\left.\mathrm{N}^{\circ} \mathrm{ARB} / 12 / 1\right)$. A la fecha de redacción de este trabajo, el laudo se encontraba en proceso de cobro, por un lado, y en proceso de anulación ante un Comité ad hoc del Centro Internacional de Arreglo de Diferencias Relativas a Inversiones (CIADI), por el otro.

5. Hoy en día es usual que los inversionistas realicen un "due diligence de derechos humanos", para identificar potenciales conflictos con antelación. La Oficina del Alto Comisionado de las 
Si a ello se suma la volatilidad en los precios del recurso respectivo, vemos que un Estado puede verse naturalmente tentado a caer en una conducta oportunista: si el precio sube, intenta renegociar las reglas del juego con la empresa minera para recibir una cuota mayor de la ganancia. En cambio, si el precio baja, un Estado puede buscar aumentar la carga tributaria o el royalty aplicable, de modo de compensar la caída en sus utilidades. En casos más extremos, los Estados pueden revocar o no renovar las concesiones o licencias, o bien intentar formas de expropiación directa o indirecta de los activos involucrados ${ }^{7}$.

Por otro lado, las ubicaciones de los proyectos suelen ser remotas y sus múltiples etapas de suministro son terreno fértil para riesgos comerciales de toda índole. Se trata de un mercado con un eslabonamiento extenso y una cadena de valor compleja, en la que participan diversos tipos de proveedores y clientes. A todo ello debe sumarse la incertidumbre propia de la industria, y especialmente la volatilidad de precios de los productos básicos.

Los riesgos del sector que hemos relatado hasta aquí acostumbran llevar a las compañías mineras a buscar estrategias de estabilización de las reglas del juego aplicables durante toda la vida del proyecto. Estos mecanismos se incluyen a nivel legislativo, en los tratados o acuerdos de inversión, o bien en los contratos celebrados entre empresas y Estados o entidades estatales. Por ejemplo, en su minuto se utilizaron intensamente las denominadas "cláusulas de intangibilidad", que lisa y llanamente prohibían al Estado cambiar de cualquier forma las reglas del contrato. Actualmente, es más común encontrar "cláusulas de congelamiento", por ejemplo, para

Naciones Unidas para los Derechos Humanos cuenta con material al respecto, <https://bit. ly/3k7uOPz>, (05/07/2021).

Por su parte, sobre la denominada "licencia social para operar" o $S L O$ por su sigla en inglés, véase M. BARNES. The 'Social License to Operate': An Emerging Concept in the Practice of International Investment Tribunals, Journal of International Dispute Settlement, 10, 2019, pp. 328-360. Ernst \& Young identificó a esta licencia como el principal riesgo comercial del sector minero en los años 2019 y 2020 (véase Q. SMith, I. TorTerola y D. Gosis. Can Foreign Investment in Latin American Mining Meet the Challenge of the Green Energy Revolution? Law.com Daily Business Review, <https://bit.ly/2VBjjXc>, (05/07/2021)).

6. J. FRY y L. BRET. N. 2, p. 3.

7. Por cierto, el Estado receptor de una inversión minera está facultado para proteger el bienestar social, el medioambiente y los derechos humanos. Aún más, es su deber hacerlo. Sin embargo, debe cumplir este deber cuidando de no afectar la viabilidad de largo plazo de los proyectos válidamente iniciados y los derechos adquiridos, o bien ofrecer la debida compensación en caso de expropiación u otra conducta de efectos equiparables. 
extender un régimen tributario durante un cierto lapso de tiempo, no obstante haber sido modificado por la ley del país respectivo; o bien "cláusulas de adaptación", que permiten ajustar los acuerdos financieros entre un inversionista minero y un Estado de manera balanceada, manteniendo así el equilibrio del contrato ${ }^{8}$.

Como adelantábamos, también es posible clasificar los riesgos asociados a la minería según las distintas etapas del proyecto en que se presentan. Inicialmente, cabe resaltar los riesgos geológicos o de exploración, como también los riesgos ambientales, sociales y políticos. En efecto, el manejo y la relación con el medio, la población local y las eventuales comunidades indígenas de la zona son de la mayor relevancia9.

Más adelante, luego de procesos de extracción, chancado, concentración o lixiviación, etc., según el recurso en cuestión, la refinación y venta de minerales y metales también tiene sus propios trances. Como hemos indicado, en esta actividad la volatilidad de los precios juega un rol mayor, de manera que los acuerdos de compra a largo plazo pueden dar lugar a una serie de disputas.

En resumidas cuentas, los conflictos pueden darse en materia de precios, suministro, volumen, calidad, transporte, royalties, reparto de utilidades, fuerza mayor, entre otros ${ }^{10}$. A modo ejemplar, si desaparece un índice y hay discrepancia sobre el nuevo método de determinación de precios, o bien si se activa una cláusula de ajuste de precios $^{11}$.

Para los fines de este trabajo, entenderemos por disputa minera cualquier clase de controversia vinculada directamente a la actividad minera en sí misma, a los derechos o permisos para llevarla a cabo,

8. J. Fry y L. Bret N. 2, p. 4.

9. Instrumentos como el Convenio 169 de la Organización Internacional del Trabajo sobre Pueblos Indígenas y Tribales en Países Independientes (1989) y la Declaración de las Naciones Unidas sobre los Derechos de los Pueblos Indígenas (2007), reconocen el deber del Estado de realizar consultas y obtener el consentimiento previo, libre e informado de las comunidades indígenas cuando sus derechos puedan verse afectados.

10. Como puede imaginarse, la pandemia del Covid-19 tuvo un impacto relevante en incontables proyectos mineros a nivel mundial durante el año 2020. Ahora bien, se espera una recuperación exitosa en el corto plazo (véase D. KURTZ, Mining sector prospers after short-lived Covid-19 shock, GlobalData, <https://bit.ly/3tEV1Ze>, (05/07/2021)).

11. J. Fry y L. BREt. N. 2, p. 7. 
o bien a los contratos requeridos para desarrollar cada etapa del negocio minero, sea con entidades públicas o privadas.

Desde otra perspectiva, los conflictos mineros propiamente tales tienen ciertas particularidades. Entre ellas, cabe destacar que la valorización de un proyecto es dificultosa en comparación a la tasación de, digamos, una central eléctrica. ¿Cómo tasar una mina antes de su entrada en producción?

A diferencia de lo que ocurre con el gas y el petróleo, puede ser muy difícil determinar con anticipación las propiedades geológicas y físicas de un depósito mineral sin antes realizar cuantiosas inversiones en perforación, testeo e ingeniería ${ }^{12}$. Lo anterior lleva a que la cuantificación de daños pueda ser compleja en un proyecto que se encuentra en sus etapas iniciales, esto es, en el importante lapso de tiempo previo a su operación ${ }^{13}$.

Así y todo, ya han surgido estándares técnicos y reglas internacionales emanados de diversas entidades reconocidas de la industria ${ }^{14}$. Si tradicionalmente se utilizaba una valorización en base a los costos - para compensar así el costo hundido de un proyecto- actualmente empieza a ser posible identificar precios de mercado con base en los futuros ingresos - con el conocido método del discounted cash flow o flujo de fondos descontados ("DCF") ${ }^{15}$. La tendencia es usar el DCF cuando los proyectos ya tienen alguna prueba de los ingresos futuros esperados. En cambio, si se trata de proyectos respecto de los cuales aún no se tiene un verdadero registro de ganancias futuras, se tiende a considerar exclusivamente el monto invertido. Cuando los distintos riesgos antes referidos no se manejan adecuadamente surgen las disputas. Pues bien, ¿cómo canalizar toda esta conflictividad potencial?

12. Ídem, p. 6 .

13. A veces de hasta una década.

14. E.g. en Australia y Canadá, con el Australasian Joint Ore Reserves Committee (JORC) y el Canada Institute of Mining (CIM), respectivamente (J. FRY y L. BRET. N. 2, p. 6).

15. Se ha identificado una tendencia de los tribunales arbitrales en el sentido de dar mayor peso a la habilidad de un proyecto para seguir operando rentablemente en el futuro que al análisis de su desempeño en el pasado (véase M. Lespiau. Future Profits vs Cost: When do Tribunals Consider a Damages Claim Too Speculative?, Ernst \& Young UK, Kluwer Arbitration Blog (2019), $<$ https://bit.ly/3ljioDQ>, (05/07/2021)). 


\section{Minería y ARbitraje}

Una herramienta que ha probado ser conveniente para atender disputas vinculadas a la minería es el arbitraje, un método de resolución de controversias que permite hacer efectivos los derechos y dar certeza en un mercado oscilante.

En efecto, en el sistema arbitral las partes pueden someterse a la decisión de un especialista o grupo de especialistas en el asunto objeto del pleito. La complejidad de la inversión en minería y del negocio minero es terreno fértil para la formación de expertos en el área ${ }^{16}$, usualmente mejor preparados en dichas materias que los jueces estatales, quienes disponen de conocimientos más bien generalistas.

Asimismo, y sin pretender hacer aquí una exposición acabada de las ventajas del arbitraje frente a otros medios de solución de disputas, nótese que la dedicación de los árbitros provee mayor celeridad que los sistemas judiciales estatales. Una vez dictado el laudo arbitral, su cobro suele ser más expedito que el de una sentencia judicial común y silvestre, puesto que las sentencias arbitrales rara vez pueden ser apeladas y su revisión está muy restringida ${ }^{17}$. Por otro lado, el arbitraje permite pactar expresamente la confidencialidad del proceso - por ejemplo, en un caso comercial en que las empresas involucradas prefieran mantener en reserva un conflicto específico. De igual forma, en el arbitraje hay más herramientas para asegurar la independencia e imparcialidad de quienes son llamados a juzgar, lo que se vuelve especialmente importante en una controversia minera internacional, cuando se busca un foro ecuánime ante el cual ventilar la disputa.

Todo ello explica que los Estados consientan en acudir a un arbitraje internacional en caso de conflicto con inversionistas extranjeros, con el fin de constituir un tribunal neutral y así promover la inversión ${ }^{18}$. Las características de la industria minera

16. J. Fry y L. BRET. N. 2, pp. 223-224.

17. La facilidad de ejecutar un laudo internacional se debe especialmente a la Convención de las Naciones Unidas sobre el Reconocimiento y la Ejecución de Sentencias Arbitrales Extranjeras (1958), conocida como la Convención de Nueva York, con 168 Estados signatarios, y al Convenio de Washington que creó el CIADI (1965), con 164 Estados signatarios.

18. A mayor abundamiento, las reglas de arbitraje son flexibles vis-à-vis los intrincados vericuetos de las reglas procesales propias de cada jurisdicción. Si bien en el arbitraje hay que pagar por 
indicadas en la sección anterior permiten explicar que el sector se haya transformado en uno de los usuarios principales del arbitraje internacional. El primer arbitraje de inversión vinculado a un proyecto minero fue en $1992^{19}$. Desde entonces, se reportan al menos noventa y cinco casos de inversión minera, sin considerar los iniciados en el último año ${ }^{20}$. A nivel global, los arbitrajes mineros se han vinculado principalmente a decisiones estatales dirigidas a incrementar impuestos y royalties, o bien a hacer más exigente la regulación ambiental. Sin embargo, según tendremos ocasión de revisar, a veces la sola existencia de disturbios sociales - por ejemplo, por ubicarse el proyecto en un área sensible desde el punto de vista ecológico o cultural- puede dar lugar a un arbitraje de inversión.

Al respecto, debe considerarse que la jurisprudencia de países típicamente mineros, como Australia y Canadá, ha jugado un rol significativo en la definición de principios aplicables a la solución de controversias en la industria. Está documentado que los tribunales de arbitraje internacional han considerado estos principios en casos similares ${ }^{21}$. Por lo demás, la inversión en el resto del mundo por parte de empresas originadas en estas sedes, como también las contribuciones de entidades internacionales -incluyendo la Organización para la Cooperación y el Desarrollo Económicos (OCDE), Naciones Unidades y el Banco Mundial— han permitido ir desarrollando un verdadero conjunto de principios internacionales del sector. Estos abarcan, incluso, la relación entre minería y derechos humanos ${ }^{22}$.

los servicios de los árbitros y, en su caso, de la institución arbitral que administre el proceso, las instituciones líderes en el mercado suelen mantener tablas de costos preestablecidos. Estos permiten cuantificar las expensas de un potencial litigio arbitral con anticipación.

19. Centro Internacional de Arreglo de Diferencias Relativas a Inversiones, Caso CIADI N ARB/92/1. Vacuum Salt Products Ltd. c. República de Ghana). Ahora bien, el caso fue rechazado por falta de jurisdicción.

20. A. ALI et al., Mining Arbitration in Latin America: Social and Environmental Issues in Investment Arbitration Cases, en J. FRY y L. BRET. N. 2, p. 201.

21. J. Fry y L. Bret. N. 2, p. 8.

22. Las controversias sobre derechos humanos propiamente tales no suelen ventilarse ante tribunales arbitrales, pero el tema está haciéndose cada vez más presente en acuerdos internacionales de inversión. Por lo demás, existe al menos un caso en que un tribunal arbitral decidió que tenía jurisdicción para conocer una demanda reconvencional del Estado en contra del inversionista por la presunta violación de sus obligaciones relativas al derecho humano de acceso al agua (Caso CIADI No. ARB/07/26. Urbaser S.A. y Consorcio de Aguas Bilbao Bizkaia, Bilbao Biskaia Ur Partzuergoa c. la República de Argentina). 
A juicio de algunos autores, la práctica del arbitraje de minería, conjugada con los estándares propios de la industria, el derecho internacional y la jurisprudencia en la materia, han venido a configurar una lex mineralia. Si bien esta se encuentra en una etapa temprana de desarrollo, probablemente se incremente junto al número de casos en el mediano plazo ${ }^{23}$. Con todo, y más allá de este incipiente derecho internacional minero, cada región presenta sus singularidades y desafíos propios. Veamos a continuación lo que podemos advertir en la región latinoamericana, para pasar posteriormente al análisis del caso chileno.

\section{El ARbitraje DE MiNERÍA EN AMÉRICA LATINA}

El último auge en el sector minero latinoamericano empezó en la década de los noventa ${ }^{24}$. Este se explicaría por la demanda creciente de economías emergentes como China e India, y por las reformas a favor de la iniciativa privada en toda la región, dirigidas a combatir el grave endeudamiento público y la hiperinflación de décadas anteriores ${ }^{25}$. Nótese que, en 2019, América Latina recibió el $28 \%$ del presupuesto global para exploraciones mineras, y solo seis países concentraron el 90\% de esa participación, a saber, Argentina, Brasil, Chile, Ecuador, México y Perúz

Para tener una idea sobre la relevancia de la industria en la región cabe considerar que, de acuerdo al Servicio Geológico de Estados Unidos, Chile tiene las mayores reservas del mundo de cobre y litio, y la séptima mayor reserva de plata. Perú tiene la mayor reserva del mundo de plata, la tercera mayor de cobre, la tercera mayor de zinc, la cuarta mayor de níquel y la quinta mayor de oro. México tiene la cuarta mayor reserva de zinc, la quinta mayor de plomo, la sexta mayor de cobre, la sexta mayor de plata y está entre los diez mayores productores de oro. Por último, Brasil tiene las

23. H. Burnett Y L. Bret. The Arbitration of International Mining Disputes, Oxford University Press, 2017, pp. 299-300.

24. G. BRIDGE. Mapping the Bonanza: Geographies of Mining Investment in an Era of Neoliberal Reform, The Professional Geographer, Vol. 56, 3, 2004, pp. 406-421.

25. B. Schorr. Oportunidades desiguales: empresas y Estado en conflictos sobre la minería en Chile, Estudios Atacameños, 57, pp. 239-255, 2018, p. 240.

26. Informe de S\&P Global, citado en <https://bit.ly/2YJ95Fq>, (05/07/2021). 
segundas mayores reservas de hierro, la tercera mayor de níquel, la cuarta mayor de estaño y la séptima mayor de oro ${ }^{27}$.

Fuera de las características propias de cada jurisdicción en lo que respecta al arbitraje doméstico, la situación del arbitraje internacional minero en América Latina ha estado marcada principalmente por el arbitraje de inversiones ${ }^{28}$, destacando aquellas controversias derivadas de asuntos sociales o ambientales ${ }^{29}$. En estas últimas nos concentraremos. Los arbitrajes de inversión minera en la región nacen por diversas razones, desde una abierta denegación de los permisos por parte de las autoridades a cargo hasta situaciones de conflicto social agudo con compromiso de la seguridad y el orden público ${ }^{30}$.

De los noventa y cinco casos de arbitraje de inversión minera que citábamos en la sección anterior, al menos veintinueve han involucrado proyectos latinoamericanos ${ }^{31}$. En diecisiete de estos últimos ya se ha dictado un laudo. Excluyendo las ocho demandas rechazadas por falta de jurisdicción del tribunal $u$ otro motivo, o bien transadas o descontinuadas, de los nueve casos restantes - en los que se revisó el fondo de la controversia- ocho concluyeron con una indemnización de perjuicios a favor del inversionista ${ }^{32} \mathrm{y}$

27. <https://latam-investor.com/2019/07/latin-american-mining/\#> (05/07/2021).

28. Por cierto, los países latinoamericanos también han sido sede de arbitrajes comerciales internacionales relativos a la minería. Un ejemplo reciente fue el caso Carbones del Cerrejón, que se litigó conforme al Reglamento de Arbitraje de la Cámara de Comercio Internacional (CCI), con la sede del arbitraje en Colombia, y cuyo proceso de anulación concluyó en diciembre de 2018 a favor de la empresa minera.

29. Hace aproximadamente una década que los centros de estudios proyectaban esta clase de controversias (véase el comentario a las predicciones de 2013 del think-tank Chatham House en N. LISNEY. Arbitration: An Effective Tool for Resolving Investor-State Disputes in the Extractive Industries?, Herbert Smith Freehills, Kluwer Arbitration Blog, <http://arbitrationblog.kluwerarbitration.com/2013/12/24/arbitration-an-effective-tool-for-resolving-investor-state-disputes-in-the-extractive-industries/> (05/07/2021)).

Esta tendencia se encuentra en línea con el pronóstico de oficinas destacadas en el área del arbitraje internacional. Por ejemplo, según un reciente informe de Freshfields Bruckhaus Deringer, los conflictos arbitrales mineros, tanto comerciales como de inversión, irán al alza en materias vinculadas al medioambiente, derechos humanos, impuestos y controles aduaneros (Freshfields Bruckhaus Deringer, International Arbitration. Illuminating the top trends in 2020, p. 15, $<$ https://bit.ly/3oQLaz3> (05/07/2021)).

30. A. Ali et al., N. 20, p. 202.

31. Ídem, p. 201.

32. Gold Reserve Inc. c. República Bolivariana de Venezuela (Caso CIADI N ARB(AF)/09/1), Quiborax S.A., Non Metallic Minerals S.A. y Allan Fosk Kaplún c. Estado Plurinacional de Bolivia (Caso CIADI N ARB/06/2), Copper Mesa Mining Corporation c. República del Ecuador (Caso PCA N ${ }^{\circ}$ 2012-2), Crystallex International c. República Bolivariana de Venezuela (Caso CIADI N ARB(AF)/11/2), Rusoro c. República Bolivariana de Venezuela (Caso CIADI 
uno terminó con el rechazo de todas sus pretensiones ${ }^{33}$. En al menos cinco de nueve casos los asuntos sociales y ambientales fueron particularmente relevantes ${ }^{34}$.

Los cambios normativos de las últimas décadas han cumplido un papel en esta litigiosidad y deben ser considerados, por lo menos, como telón de fondo para el análisis. A modo ejemplar, en Ecuador la propia Constitución de 2008 otorga a las comunidades indígenas el derecho a una consulta previa y obligatoria sobre cualquier plan o proyecto que pueda tener un impacto ambiental o cultural en sus tierras, el derecho a recibir parte de los beneficios de los referidos proyectos, como asimismo a obtener una reparación por cualquier daño social, cultural o ambiental que pueda ser causado por proyectos extractivos ${ }^{35}$. Como es evidente, una disposición constitucional de este tipo podría tener un efecto considerable en materias mineras.

Bolivia, Chile, Colombia, Perú y Venezuela, todos países con actividad minera significativa, han adoptado en el último tiempo una serie de reglas similares, tendientes a proteger el medioambiente y los derechos de las comunidades locales, con especial énfasis en las comunidades indígenas ${ }^{36}$.

En particular, en el caso de la canadiense Gold Reserve ${ }^{37}$ un tribunal de inversiones consideró que la revocación de un permiso de construcción por parte de Venezuela fundada en el impacto en el ambiente y las comunidades locales, sí podía constituir una violación al estándar de Trato Justo y Equitativo - consagrado en incontables tratados bilaterales de inversión- si el inversionista ya había cumplido con las obligaciones que le imponía la concesión.

No. ARB(AF)/12/5), Bear Creek Mining Corporation c. República del Perú (Caso CIADI No. ARB/14/21), South American Silver Limited c. Estado Plurinacional de Bolivia (Caso PCA No. 2013-15) y Dominion Minerals Corp. c. República de Panamá (Caso CIADI No. ARB/16/13).

33. Anglo American PLC c. República Bolivariana de Venezuela (Caso CIADI No. ARB(AF)/14/1).

34. A. Ali et al., N. 20, p. 202.

35. Constitución de la República del Ecuador, Artículo 57, RO No. 449, 20/10/2008.

36. A. Ali et al., N. 20, p. 201. Por ejemplo, en Colombia destaca la Constitución Política de 1991 (Artículo 330); en Venezuela tanto la Constitución de 1999 (Artículos 119 al 126) como la Ley Orgánica de Pueblos y Comunidades Indígenas de 2005 (Artículos 10-18); en Chile, el Convenio 169 antes citado entró en vigencia en 2009, sin perjuicio de lo que se dirá en la sección siguiente sobre la nueva normativa constitucional en ciernes; en Perú se dictó la Ley 29.785 de 2011 sobre derecho a la consulta previa de los pueblos indígenas u originarios; y en Bolivia se dictó la Ley 535 de 2014 sobre Minería y Metalurgia (Artículos 19, 40, y del 207 a 213).

37. Gold Reserve Inc. c. República Bolivariana de Venezuela. 
Para cuantificar los daños, el tribunal utilizó el método DCF. De un total de 1.700 millones de dólares reclamados, el tribunal concedió 713 millones.

Otro tribunal de inversiones juzgó en el caso de la chilena Quiborax ${ }^{38}$ que Bolivia había expropiado ilegalmente 11 concesiones mineras, violado el estándar de Trato Justo y Equitativo, y adoptado medidas arbitrarias y discriminatorias luego de cancelar una licencia ambiental y revocar una concesión minera para explotar ulexita en el Salar de Uyuni. Todo ello tras graves protestas. Al igual que en el caso anterior, el tribunal cuantificó los daños aplicando el método DCF. De los 151 millones de dólares reclamados, el tribunal condenó al pago de casi 49 millones.

En el caso de la canadiense Copper Mesa ${ }^{39}$, marcado por la fuerte resistencia social y una serie de episodios violentos, el inversionista reclamó por expropiación y violación de Ecuador a los estándares de Trato Justo y Equitativo, Protección y Seguridad Plenas, y Trato Nacional, en relación a sus concesiones en Junín, Chaucha y Telimbela. El tribunal de inversiones estimó que había existido una expropiación arbitraria y sin compensación de las concesiones de Junín, y asimismo una expropiación indirecta de las concesiones de Chaucha. Nótese que el proyecto aún estaba en etapa de exploración. Al momento de cuantificar los daños, el tribunal consideró especialmente la conducta del inversionista, quien habría sido en parte responsable de sus propios perjuicios, tras enfrentarse violentamente a la población local. El tribunal usó un método basado en los costos del proyecto. Así, estimó que la minera había contribuido a su propio daño en al menos un $30 \%$. En definitiva, se condenó a Ecuador al pago de aproximadamente 20 millones de dólares.

En el caso South American Silver ${ }^{40}$, las comunidades Aymara y Quechua se opusieron fuertemente a un proyecto minero en Bolivia. Laviolencia delconflictoincluyósecuestros,conalmenosunfallecido. El Estado boliviano canceló la concesión minera de la compañía constituida en Bermudas. El tribunal castigó al inversionista por

38. Quiborax S.A., Non Metallic Minerals S.A. y Allan Fosk Kaplún c. Estado Plurinacional de Bolivia.

39. Copper Mesa Mining Corporation c. República del Ecuador.

40. South American Silver Limited c. Estado Plurinacional de Bolivia. 
contribuir al agravamiento del conflicto social, generando discordia entre distintos grupos indígenas. En consideración a ello, el Estado habría estado justificado para cancelar la concesión, como en una expropiación legal. La única infracción declarada fue la falta de una compensación adecuada. Ahora bien, la indemnización se limitó a los costos del proyecto. De casi 386 millones de dólares reclamados, el tribunal condenó al pago de aproximadamente 19 millones.

En Perú, los violentos conflictos sociales entre el inversionista canadiense Bear Creek ${ }^{41}$ y las comunidades indígenas Aymara incluyendo al menos seis manifestantes fallecidos- llevaron a la autoridad a revocar un decreto que permitía explotar las concesiones mineras en Santa Ana, cerca de la frontera con Bolivia. El inversionista demandó alegando una expropiación indirecta. Al igual que en el caso Copper Mesa, aún no se contaba con estudios de impacto ambiental y social, pues faltaban los acuerdos con las comunidades locales. Con todo, el tribunal consideró que la revocación del decreto no se justificaba por el conflicto social, en atención a que el gobierno había apoyado las acciones del inversionista. En consecuencia, se decidió que había existido una expropiación indirecta, la que había impactado económicamente en la inversión y violado las legítimas expectativas del inversionista. Ahora bien, debido a la magnitud del conflicto, el tribunal no pudo concluir que el proyecto fuera viable en el corto plazo. De esta manera, solo ordenó compensar por los costos y no por la futura rentabilidad del proyecto. De los más de 522 millones de dólares reclamados, se condenó al pago de aproximadamente 18 millones.

Se ha afirmado que los riesgos sociales y ambientales podrían incluso llegar a afectar la jurisdicción de un tribunal arbitral internacional. En efecto, si una inversión no se realiza de acuerdo a la normativa local sobre autorizaciones sociales o ambientales, un Estado podría verse inclinado a negar la protección que ofrezca el tratado aplicable ${ }^{42}$.

De igual forma, según hemos visto en los casos relatados, el inversionista minero puede ver reducida su indemnización por la conducta que haya tenido frente a las comunidades locales $y$,

41. Bear Creek Mining Corporation c. República del Perú.

42. A. Ali et al., N. 20, pp. 208-209. 
asimismo, de acuerdo a la viabilidad del proyecto, todo ello según la convicción que alcance el tribunal en el caso concreto ${ }^{43}$.

La violencia de los conflictos y las cuantiosas condenas indemnizatorias en casos como los antes señalados y otros fuera del ámbito minero, han generado múltiples críticas al sistema de protección de inversiones en América Latina ${ }^{44}$.

El tema es sensible en la región, considerando que el Convenio de Washington sobre Arreglo de Diferencias Relativas a Inversiones entre Estados y Nacionales de Otros Estados de 1965, que creó el Centro Internacional de Arreglo de Diferencias Relativas a Inversiones (CIADI) fue denunciado por Bolivia en 2007, por Ecuador en 2009 y por Venezuela en 2012 ${ }^{45}$. Estos últimos países se dedicaron con especial ahínco a deshacer sus tratados bilaterales de inversión. Y si bien en su oportunidad esto pareció un regreso a la "Doctrina Calvo"46, en una nota más optimista se puede destacar que tanto Ecuador como Bolivia ya han redactado nuevos modelos de tratados bilaterales de inversión, que Ecuador volvió a firmar el Convenio del CIADI en junio de 2021, y que Chile, México y Perú negociaron el Tratado Integral y Progresista de Asociación Transpacífico (CPTPP), uno de los esquemas de integración económica más relevantes en el Asia Pacífico.

En lo que respecta a la tarea propia de los Estados latinoamericanos, se ha dicho que, junto con promover la protección social y ambiental frente a proyectos mineros, deberían tener un rol activo en el acercamiento de las empresas con las comunidades locales, de manera que las inversiones sean socialmente aceptadas ${ }^{47}$.

\footnotetext{
43. Ídem, pp. 209-210.

44. Por ejemplo, un Informe de 2019 titulado "Casino del Extractivismo”, de J. Moore y M. PÉrez Rocha (Mining Watch, Institute for Policy Studies y Center for International Environmental Law-CIEL) estudió 38 demandas de arbitraje de inversión. En el Informe se explica que un tercio de los casos ha estado relacionado a los derechos indígenas y el consentimiento local, al tiempo que en más de la mitad de los casos se habrían impugnado acciones de autoridades que se tomaron por razones ambientales o sanitarias. El Informe propone priorizar la protección de los derechos humanos y en particular de pueblos indígenas y el medioambiente, por sobre los derechos de inversionistas extranjeros.

45. Por lo demás, Brasil nunca ha suscrito el Convenio de Washington, decidiendo buscar otras formas de atraer la inversión extranjera, tales como su trayectoria sin expropiaciones, un Poder Judicial independiente, una regulación favorable al arbitraje.
}

46. Conforme a la cual los extranjeros deben someterse a los tribunales locales.

47. A. Ali et al., N. 20, p. 211 
Como se advierte hasta aquí, el arbitraje de minería en América Latina ha estado marcado por conflictos sociales violentos, jugando un rol relevante la protección de las comunidades indígenas y el medioambiente. Habiendo relatado a grandes rasgos la situación regional, entremos de lleno a la revisión del estado de cosas en Chile.

\section{LA SOLUCiÓN DE DISPUTAS MINERAS EN CHILE}

\subsection{Chile: un país minero}

La minería es favorecida en Chile por su geografía y conformación geológica. Se ha llegado a afirmar que el porvenir de sus habitantes está indisolublemente ligado al acierto con que se regule e impulse el progreso de la actividad minera ${ }^{48}$. Esta última se convirtió ya en el siglo XIX en el sector más importante de la economía chilena ${ }^{49}$ y es aún hoy una de las principales fuentes productoras de divisas ${ }^{50}$. Además, es esencial para el empleo en zonas apartadas de las principales urbes del territorio nacional.

El rubro de la industria más desarrollado es la minería del cobre ${ }^{51}$, respecto de la cual Chile es el primer productor mundial y el mayor exportador. El rubro tiene una historia controversial. Hace exactamente medio siglo, el año 1971, las empresas extranjeras que formaban la denominada "Gran Minería del Cobre" fueron expropiadas mediante la Ley 17.450. El Estado deChile dispuso queel monto de la indemnización podría reducirse en base a las "rentabilizadas excesivas" que hubieren obtenido las empresas nacionalizadas, y pagarse en un plazo de hasta treinta años. Por su parte, el Decreto Ley 1.350 de 1976 reguló la Corporación Nacional del Cobre de Chile (CODELCO), empresa estatal con personalidad jurídica y patrimonio propios, que ejerce los derechos que adquirió el Estado en las empresas expropiadas ${ }^{52}$.

48. S. LiRa. Curso de Derecho de Minería, quinta edición, Editorial Jurídica de Chile, 2009, p. 12.

49. B. SCHORR. N. 25 , p. 242.

50. A pesar de la crisis del Covid-19, en 2020 la minería significó exportaciones por 37.409 millones de dólares al 15 de diciembre (lo que representa un 2,6\% más que en 2019), en un marco de exportaciones totales por 67.416 millones de dólares (Fuente: Banco Central de Chile).

51. De los 37.409 millones de dólares por exportaciones mineras antes indicados, el cobre fue responsable de 33.876 millones.

52. Entre ellas, Anaconda, Kennecott Copper Corporation y Cerro Corporation. CODELCO es actualmente la empresa productora de cobre más grande del mundo. Asimismo, es la empresa que más contribuye a la economía chilena (véase $<$ https://bit.ly/3azzacA $>(06 / 07 / 2021)$ ). 
$\mathrm{Al}$ cobre le siguen en importancia el molibdeno, el oro, la plata, el litio, el hierro, el plomo, el zinc y el manganeso. En la minería no metálica cabe mencionar al salitre y el yodo, entre otros. Si bien la Ley 17.450 estableció el dominio del Estado sobre las minas, dejando a los propietarios mineros como meros concesionarios, lo cierto es que más tarde la Constitución Política de 1980 dispuso un dominio especial del Estado sobre los minerales, restableciendo la solidez de los derechos de particulares ${ }^{53}$. A partir de entonces la materia se reguló ampliamente en la Ley 18.097 Orgánica Constitucional sobre Concesiones Mineras de 1982, la Ley 18.248 que contiene el Código de Minería de 1983 y su Reglamento de 1987.

Una característica relevante del derecho chileno es que todos los derechos mineros se constituyen y extinguen por resolución judicial, y no por vía administrativa como ocurría en la normativa anterior a 1980. Ello permite separar el otorgamiento y la extinción de derechos mineros de las decisiones de funcionarios de la administración, comúnmente vinculados al gobierno de turno.

La Ley Orgánica Constitucional sobre Concesiones Mineras reconoce al titular de la concesión un derecho de propiedad sobre esta, y dispone que la privación de las facultades de iniciar o continuar la exploración, extracción y apropiación de las sustancias objeto de concesión constituye una privación de los atributos o facultades esenciales del dominio de la misma ${ }^{54}$. Se remarca además el derecho del concesionario para defender su concesión por todos los medios que franquea la ley, tanto respecto del Estado como de particulares ${ }^{55}$.

Esta institucionalidad probó ser efectiva para incentivar la minería. Por ejemplo, entre 1990 y 2001, Chile fue el mayor recipiente de inversiones privadas en minería de toda la región, con un total de un $18 \%{ }^{56}$. Según explicamos en la sección introductoria, la industria minera es propensa a conflictos de toda índole, y por ello es que estos han existido no obstante la sólida normativa vigente en materias mineras. Revisemos, en primer lugar, lo ocurrido a nivel

53. S. LiRA. N. 48, p. 30.

54. Ley 18.097 Orgánica Constitucional sobre Concesiones Mineras, Artículo 6.

55. Ídem, Artículo 9.

56. G. BRIDGE. N. 24. 
local, con disputas sometidas al derecho interno, para luego pasar al análisis de las disputas internacionales.

\subsection{DispuTAS DOMÉSTICAS}

Desde ya cabe resaltar que ha habido disputas mineras significativas resueltas a nivel nacional, e incluso ante tribunales estatales (esto es, no arbitrales), a pesar de comprometer capitales extranjeros. A modo ejemplar, puede mencionarse el litigio entre la estatal CODELCO y la inglesa Anglo American en el año 2011, probablemente el juicio de mayor cuantía de la historia judicial chilena ${ }^{57}$.

La filial de Anglo American en Chile pretendía vender a la japonesa Mitsubishi un porcentaje relevante de sus acciones en la compañía minera ex Disputada de Las Condes (hoy mina Los Bronces $^{58}$ ), lo que presuntamente habría vulnerado un derecho de opción de compra otorgado a CODELCO en 1978. El juicio concluyó con un acuerdo transaccional: Anglo American mantuvo el control de la mina, pero el $29,5 \%$ fue adquirido por un joint venture entre CODELCO y la también japonesa Mitsui.

Nótese que Anglo American es una empresa cuya matriz se encuentra en Reino Unido. La inversión de la compañía inglesa estaba amparada en el ya derogado Decreto Ley 600, que a la sazón contenía el Estatuto de la Inversión Extranjera ${ }^{59}$. En 1997, Chile había firmado un Acuerdo para la Promoción y Protección de las Inversiones con el Reino Unido, el que se encontraba vigente y que, de hecho, incluía una "cláusula paraguas", esto es, aquella que exige al Estado receptor de una inversión cumplir cualquier compromiso contractual asumido con un inversionista de la otra parte. Así y todo, la controversia fue litigada ante un tribunal estatal chileno ${ }^{60}$, sin llegar a instancias internacionales.

57. Sobre los 6.700 millones de dólares.

58. Se trata de un yacimiento de cobre y molibdeno, ubicado en la zona central de Chile, en el límite entre la Región Metropolitana y la Región de Valparaíso.

59. Esta normativa especial permitía al inversionista extranjero celebrar un contrato con el Estado de Chile, a través del Comité de Inversiones Extranjeras, a fin de asegurar los derechos del inversionista (no discriminación, acceso al mercado cambiario formal, invariabilidad tributaria, entre otros).

60. Causa Rol C-35893-2011 seguida ante el 14 Juzgado Civil de Santiago. 
En cuanto al arbitraje propiamente tal $^{61}$, el arbitraje de minería en Chile también es relevante a nivel doméstico. Por ejemplo, la institución arbitral más importante del país, a saber, el Centro de Arbitraje y Mediación de la Cámara de Comercio de Santiago (CAM Santiago), reporta que los casos de arbitrajes nacionales vinculados a materias de minería y energía han representado hasta un $10 \%$ del total de $\operatorname{casos}^{62}$.

Por otro lado, nótese que en 2021 la Cámara Minera de Chile anunció la creación de un Centro de Arbitraje y Mediación Minera, especializado en disputas de la industria.

Por ejemplo, en 2012 hubo una licitación por la recuperación del cobre y molibdeno del relave ${ }^{63}$ de la División Andina de CODELCO, en la Región de Valparaíso. El proceso fue adjudicado a Minera Valle Aconcagua, vinculada al Grupo italiano Astaldi junto con inversionistas locales. La planta que prestaría el servicio de maquila no presentó los niveles de recuperación proyectados. Luego de una serie de intentos de mejoras sin mayor resultado, Minera Valle Aconcagua demandó en sede arbitral - por mejoras y gastos- 38 millones de dólares, más pérdidas operativas y financieras por 20 millones más. Por su parte, CODELCO presentó cuatro demandas subsidiarias contra Minera Valle Aconcagua. La empresa estatal argumentó que no se había dado término a la planta y por lo mismo se le adeudaba una compensación, insistiendo en el incumplimiento de los niveles de recuperación. Adicionalmente, CODELCO pidió la aplicación de multas y valorizó el cobre no recibido en el proceso de maquila. El total del pago exigido por CODELCO ascendía a 120 millones de dólares. El árbitro local rechazó las demandas de CODELCO. En efecto, solo accedió a que fuera indemnizada en dos millones de dólares, ordenando que en definitiva fuera la estatal quien pagara a Minera Valle Aconcagua la suma de 41 millones de dólares. Ambas partes recurrieron ante la Corte de Apelaciones de Santiago, pero finalmente llegaron a un acuerdo transaccional.

61. Chile tiene un sistema de arbitraje dualista, esto es, con normativa diversa para el arbitraje local y el internacional.

62. Estadística 2014-2015 versus Estadística 2020 del Centro de Arbitraje y Mediación de la Cámara de Comercio de Santiago.

63. El relave es un sólido finamente molido, que es descartado en operaciones mineras. 


\subsection{Disputas internacionales}

Como se sabe, en el plano del arbitraje internacional corresponde distinguir sus dos variantes: el arbitraje comercial y el arbitraje de inversiones. Revisemos en forma sucinta las reglas aplicables a cada uno para luego abordar la experiencia chilena.

Por una parte, el arbitraje comercial internacional está regulado en Chile en la Ley 19.971, que reproduce la Ley Modelo sobre la materia de la Comisión de las Naciones Unidas para el Derecho Mercantil Internacional (CNUDMI), aunque sin las modificaciones del año 2006. De acuerdo a esta normativa, en Chile se considera que el arbitraje es internacional si las partes del acuerdo de arbitraje tienen sus establecimientos en Estados diferentes al momento de su celebración ${ }^{64}$; si la sede del arbitraje o el lugar del cumplimiento de una parte sustancial de las obligaciones de la relación comercial o el lugar con el cual el objeto del litigio tiene una relación más estrecha se encuentra en un país distinto a aquel donde las partes tienen sus establecimientos ${ }^{65}, \mathrm{o}$ - finalmente- si las partes acuerdan que el objeto del arbitraje está relacionado con más de un Estado ${ }^{66}$. En relación a esta última hipótesis, como vimos, es usual que empresas extranjeras operen en Chile mediante sociedades relacionadas constituidas localmente, de manera que perfectamente podrían tener interés en pactar un arbitraje comercial internacional para el caso que surja una controversia ${ }^{67}$.

Por su parte, la expresión "comercial" se interpreta en sentido amplio, abarcando todas las cuestiones que se plantean en las relaciones de esta índole, contractuales o no. Por ejemplo, en lo que podría interesar a las disputas mineras, se incluye cualquier operación de suministro o intercambio de bienes o servicios, acuerdos de distribución, representación o mandato comercial, arrendamiento de bienes con opción de compra, construcción de obras, consultoría, ingeniería, concesión de licencias, inversión, financiación, seguros, acuerdo o concesión de explotación,

64. Ley 19.971, Artículo 1 No. 3) letra a). Si una de las partes tiene más de un establecimiento, se considera el que guarde una relación más estrecha con el acuerdo de arbitraje (Artículo 1, No. 4 letra a).

65. Ídem, Artículo 1 No. 3) letra b) numerales i) y ii).

66. Ídem, Artículo 1 No. 3 letra c).

67. E. MereminskayA. Arbitraje Comercial Internacional en Chile. Desafios y desarrollo, Thomson Reuters, 2014, pp. 21-23. 
asociaciones de empresas y otras formas de cooperación industrial o comercial, transporte de mercancías o de pasajeros por vía aérea, marítima, férrea o por carretera ${ }^{68}$.

Como se advierte, Chile es un país favorable al arbitraje internacional. En 1975 ratificó la Convención de las Naciones Unidas sobre el Reconocimiento y la Ejecución de Sentencias Arbitrales Extranjeras de 1958, conocida como la Convención de Nueva York. Por lo demás, es de hacer notar que, a la fecha, ninguna acción de nulidad ${ }^{69}$ ha sido acogida en Chile por las cortes superiores de justicia.

Por otra parte, en lo que respecta al arbitraje de inversiones, Chile es parte del Convenio de Washington que creó el CIADI en 1965, el que fue ratificado el 24 de septiembre de 1991. Adicionalmente, el país ha suscrito varias docenas de tratados bilaterales y acuerdos multilaterales de inversión, junto con otras tantas de tratados de libre comercio que incluyen disposiciones relativas a la protección de inversiones ${ }^{70}$.

Al respecto, en el caso de inversionistas que hubieren procedido a suscribir un contrato con el Estado receptor, la infracción de lo pactado por parte de un Estado podría dar pie al arbitraje acordado contractualmente $\mathrm{y}$, asimismo, provocar una demanda ante un tribunal arbitral establecido a través de un acuerdo en materia de inversión extranjera ${ }^{71}$.

Lo anterior era perfectamente cierto para el ámbito minero chileno hasta la entrada en vigencia en 2016 de la Ley 20.848, que fijó un nuevo marco legal para la inversión extranjera directa ${ }^{72}$. En virtud de la nueva normativa, la autoridad a cargo de la inversión extranjera ya no puede celebrar contratos con inversionistas en

68. Ley 19.971, Artículo 2 letra g).

69. Ídem, Artículo 34.

70. Véase $<$ https://bit.ly/2YO9yXp $>(06 / 07 / 2021)$.

71. E. Mereminskaya. N. 67, p. 183. Cfr. G. TAWIL. The Distinction Between Contract Claims and Treaty Claims: An Overview, Montreal: Conferencia dictada en el International Council for Commercial Arbitration (ICCA) Congress 2006 - International Arbitration: Back to Basics?

72. Si bien la normativa interna chilena impedía someter los contratos de inversión extranjera del Decreto Ley 600 a tribunales extranjeros (Decreto Ley 2.349 de 1978, Artículo 7), dichas disposiciones estaban superadas por los compromisos internacionales asumidos por el Estado de Chile.

Cabe señalar, además, que el derogado Decreto Ley 600 contenía una garantía de invariabilidad tributaria especial con respecto al impuesto especíico a la actividad minera (Artículo 11 ter). 
representación del Estado de Chile ${ }^{73}$. Con todo, la nueva ley dispuso la conservación de los derechos y obligaciones contemplados en los contratos de inversión extranjera suscritos con anterioridad al año 2016.

En general, el elemento principal que debe ser ponderado para determinar si la conducta del Estado puede ser discutida ante un tribunal arbitral de inversiones es si la disputa surgió de una inversión. Típicamente, si hay un mero intercambio de bienes a cambio de un precio se estima que solo hay una compraventa comercial y no una inversión. En cambio, si hay una cierta duración de la relación contractual, un volumen relevante de la contribución, presencia del factor-riesgo asumido por el inversionista, y eventualmente -aunque es particularmente discutido- una contribución al desarrollo del Estado receptor, entonces se puede considerar que se está efectivamente ante una inversión ${ }^{74}$.

En el caso de Chile, los denominados "Acuerdos de Protección y Promoción de Inversiones" estilan incluir un concepto amplio y no taxativo de lo que se entiende como inversión. En tal sentido, múltiples tratados incluyen explícitamente dentro de los tipos de inversión protegidos a las concesiones, incluidas aquellas para explorar, extraer o explotar recursos naturales. La mayoría establece como inversión, en términos incluso más amplios, a los derechos contractuales en general, sin que necesariamente se sitúen en el marco de una concesión.

La doctrina anticipa que, en cada situación concreta, habrá que discutir si se presentan o no los límites inherentes al concepto de inversión, lo que será más fácil en el caso de los contratos de concesión, en atención a su envergadura y la participación de los poderes públicos en su perfeccionamiento ${ }^{75}$. El asunto, entonces, se debe discutir caso a caso, y la clave usualmente está en revisar

73. Nótese que, a partir de 2016, Chile pasó cinco años sin grandes inversiones mineras realizadas desde cero o Greenfield. Solo hubo inversiones Brownfield, que son aquellas que aprovechan instalaciones ya existentes, tales como expansiones o bien un paso a los sulfuros por agotamiento de óxidos. En cambio, otros países de la región — como Perú— sí desarrollaron proyectos nuevos en el mismo período.

74. E. MereminsKaya. N. 67, pp. 186 y ss., donde se explica el conocido "test Salini", sus desarrollos y críticas posteriores (Salini Costruttori S.p.A. e Italstrade S.p.A. c. Reino de Marruecos, Caso CIADI No ARB/00/4, decisión sobre la jurisdicción de 16 de julio de 2001).

75. Ídem, p. 191. 
si el proyecto o actividad objeto de análisis cumple con la noción de inversión contenida en el acuerdo o tratado de inversiones respectivo.

En simple, para que exista un arbitraje comercial la regla generalísima es que haya existido un incumplimiento contractual ${ }^{76}$. Pues bien, sobre la base de ese mismo incumplimiento se podría intentar llegar a un tribunal arbitral de inversiones, en caso que la conducta constituya también una infracción del tratado de inversiones correspondiente, esto es, una vulneración del derecho internacional. Naturalmente, además del contenido del contrato, habrá que atender a las partes del mismo. En efecto, solo hay arbitraje inversionista-Estado cuando ha intervenido el Estado o una entidad estatal, en la medida que así sea recogido por el tratado respectivo. Asimismo, en principio una violación del tratado exigiría una actuación agravada y soberana del Estado, salvo que exista una cláusula paraguas que permita extender responsabilidad internacional por incumplimientos contractuales de cualquier índole ${ }^{77}$.

¿Cuál ha sido la experiencia específica de Chile con el arbitraje de minería internacional? Ya hemos hecho referencia a la extensa cadena de suministro que aplica en el negocio minero. Pues bien, si se presenta uno de los supuestos contenidos en la Ley de Arbitraje Comercial Internacional, podrían surgir procesos internacionales en contratos mineros de toda clase, desde consultoría e ingeniería hasta cooperación industrial.

En los últimos años, el litio ha jugado aquí un rol importante. Desde 1979 que el litio está declarado como un recurso estratégico en Chile ${ }^{78}$. La agencia gubernamental denominada Corporación de

76. Teóricamente, también puede acordarse un arbitraje para resolver una disputa extracontractual.

77. E. MereminsKaya. Demandas contractuales ante los tribunales internacionales a la luz de los APPIs suscritos por Chile, Revista de la Sociedad de Derecho Internacional de Chile, 2010, $\mathrm{N}^{\mathrm{o}}$ 1, p. 52.

Si bien se discute si una cláusula de solución de controversias incluida en el contrato puede limitar la jurisdicción del tribunal de inversiones propio del tratado, una forma novedosa de aclarar toda duda y evitar la existencia de procesos paralelos consiste en exigir al inversionista una renuncia de su derecho para iniciar o continuar un procedimiento relativo a los mismos hechos que causan la controversia, en forma previa a proceder al arbitraje internacional de inversiones. Así lo exigen, por ejemplo, los Tratados de Libre Comercio de Chile con Canadá y Estados Unidos (Ibíd., p. 61).

78. Decreto Ley 2.886 de 1979. 
Fomento de la Producción (CORFO) es la dueña de las pertenencias mineras en el Salar de Atacama. Ahora bien, hay dos empresas privadas que operan en el Salar en virtud de contratos especiales de operación ${ }^{79}$. Se trata de la norteamericana Albemarle y la chilena $\mathrm{SQM}^{80}$. Ambas suscribieron contratos con CORFO a partir de los años ochenta.

En el caso de SQM, esta ha tenido controversias con CORFO, entre otras materias, por el pago de regalías, siendo objeto de un arbitraje local en el CAM Santiago y concluyendo con un acuerdo conciliatorio en $2018^{81}$. Ahora bien, la nueva presencia relevante de inversionistas extranjeros podría abrir la posibilidad de un arbitraje de inversiones en el futuro ${ }^{82}$.

En el caso de Albemarle, el asunto efectivamente escaló al nivel internacional. En efecto, desde 2018 que el Gobierno de Chile amenazaba con iniciar un arbitraje comercial internacional conforme a las Reglas de Arbitraje de la Cámara de Comercio Internacional (CCI), acordadas por las partes en la cláusula de resolución de controversias del contrato vigente, por el presunto incumplimiento de la minera de litio respecto de un anexo celebrado en 2016. Pues bien, la solicitud de arbitraje fue presentada en febrero de 2021. En particular, según trascendió, se habría acusado a Albemarle de no pagar royalties, adeudando aproximadamente 15 millones de dólares en comisiones al Estado. En el pasado se había acusado a la misma Albemarle de incumplir su obligación de proporcionar un precio preferencial respecto del $25 \%$ de su producción anual a las compañías que producen materiales para baterías en Chile ${ }^{83}$.

Como se aprecia, queda abierta la posibilidad de que la relación entre estas empresas privadas y el Estado chileno escale incluso al

79. Según lo autoriza el Artículo 8 del Código de Minería

80. En 2018 la china Tianqi adquirió una participación del $24 \%$ de SQM de manos de la canadiense Nutrien, en la mayor operación realizada en la historia de la Bolsa de Comercio de Santiago a esa fecha. El remate superó los 4.000 millones de dólares.

81. El arreglo implicó, entre otros, el pago de aproximadamente 20 millones de dólares a CORFO, la modificación del contrato para aumentar la renta de arrendamiento al nivel del contrato que tenía Albemarle, la reserva de hasta un $25 \%$ de la producción para su venta a interesados en agregar valor al litio en Chile, el aumento de la cuota autorizada de extracción, el cumplimiento irrestricto de la normativa ambiental, la restitución de derechos de agua y mineros al Estado, y un cambio del gobierno corporativo de la compañía.

82. Cabe señalar que el acuerdo conciliatorio mantuvo una cláusula de solución de controversias conforme al Reglamento de Arbitraje del CAM Santiago.

83. Véase $<$ https://bit.ly/2YKWfqE $>(06 / 07 / 2021)$ y $<$ https://bit.ly/3ashcZE $>(06 / 07 / 2021)$. 
ámbito del arbitraje inversionista-Estado. En lo que refiere a este tipo de procesos, interesantemente Chile no ha tenido controversias mineras ante tribunales internacionales. De los cinco casos en que se ha visto involucrado el Estado chileno ${ }^{84}$, ninguno ha versado sobre materias de minería.

La escasa participación de Chile en arbitrajes de inversión impresiona en comparación a la situación de otros países en la región. Por vía de ejemplo, Venezuela ha sido demandada en más de 40 ocasiones y Argentina en más de 60.

Como es dable concluir hasta aquí, la potencialidad de casos de arbitraje de inversión minera en Chile es evidente. En efecto, fuera de los importantes capitales nacionales —estatales y privadosinvolucrados en el desarrollo de la minería en el país, existen grandes inversionistas mineros provenientes de Australia, Canadá, China, Estados Unidos, Japón, Reino Unido, Suiza, entre otros. Estos inversionistas bien podrían aprovechar los derechos que les corresponden por tratados bilaterales de inversión o acuerdos equiparables ${ }^{85}$ en caso que el Estado chileno los infrinja, todo ello sujeto al cumplimiento de los requisitos aplicables al caso específico.

Cabe señalar, además, que el país ya tiene experiencia con las temáticas litigiosas que abundan en América Latina y que hemos relatado en la sección anterior ${ }^{86}$. A modo ejemplar, en septiembre de 2020 un Tribunal Ambiental del norte de Chile confirmó el cierre definitivo del proyecto minero Pascua Lama, propiedad de la canadiense Barrick, junto a una multa de nueve millones de dólares ${ }^{87}$. Se trataba de un proyecto binacional en la frontera

84. Victor Pey Casado y Fundación Española Presidente Allende c. República de Chile (Caso CIADI No. ARB/98/2); MTD Equity Sdn. Bhd. y MTD Chile S.A. c. República de Chile (Caso CIADI No. ARB/01/7); Sociedad Anónima Eduardo Vieira c. República de Chile (Caso CIADI No. ARB/04/7), Carlos Ríos Velilla y Francisco Javier Ríos Velilla c. República de Chile (Caso CIADI No. ARB/17/16) e Interconexión Eléctrica S.A. E.S.P. c. República de Chile (Caso CIADI No. ARB/21/27). Por su parte, entre los casos mineros vinculados a inversionistas chilenos en el extranjero se encuentran los de Tethyan Copper y Quiborax, ambos ya citados.

85. La totalidad de los países citados tienen acuerdos de protección de inversiones con Chile.

86. Al cierre del primer semestre del año 2021, el denominado "Observatorio de Conflictos Mineros de América Latina" reportaba un registro histórico de 284 casos de conflicto en la región, de los cuales al menos 49 habrían involucrado o involucrarían actualmente a Chile.

87. El proyecto no cumplió con su Resolución de Calificación Ambiental, lo que llevó a la aplicación de diversas sanciones por infracciones calificadas como graves y gravísimas, relativas al monitoreo de glaciares y glaciaretes, el monitoreo y descarga de aguas de contacto al río Estrecho, y la utilización de una metodología de cálculo de niveles de alerta de calidad de aguas 
chileno-argentina, al sur del Desierto de Atacama, por más de 8.000 millones de dólares. El yacimiento de oro, plata y cobre, iniciado en 2001, estaba cerrado desde 2013 por orden de la Superintendencia de Medioambiente, ratificada por la Corte de Apelaciones de Copiapó ${ }^{88}$.

Ha llamado la atención el contraste entre el devenir del proyecto Pascua Lama, privado, vis-à-vis el proyecto El Salvador de CODELCO, estatal, ambos ubicados en la Región de Atacama. Se ha planteado que la diferencia se explicaría por el contexto local, pero especialmente por el origen y la propiedad de la compañía minera involucrada en uno y otro caso $^{89}$. ¿Por qué Barrick no continuó a instancias internacionales, por ejemplo, para asegurar un tribunal independiente e imparcial? De acuerdo a la información pública, la compañía pareciera haber descartado la existencia de un reclamo en tal sentido. Desde luego, aceptó la decisión del Tribunal Ambiental sin reparos, al no apelar de la misma. En el segundo semestre de 2020, el director ejecutivo de la compañía señaló que buscarían plantear un nuevo proyecto en la zona, que cumpliera con todos los aspectos técnicos, económicos y sociales ${ }^{90}$.

En fin, nótese que inversionistas chilenos en el extranjero sí han acudido al arbitraje de inversión en materias mineras ${ }^{91}$.

\subsection{El proceso constituyente en curso}

Es indudable que una de las grandes virtudes del sistema legal chileno en las últimas décadas ha sido la certeza jurídica otorgada a los derechos mineros luego de la crisis de expropiaciones de 1971.

no autorizada, que utilizaba niveles más permisivos que los contemplados en la calificación ambiental.

88. Un acuerdo entre la empresa minera y la Junta de Vigilancia de la Cuenca del Río Huasco —río que abastecía a comunidades indígenas - fue objeto de un arbitraje doméstico ante el CAM Santiago. En 2016, la Junta de Vigilancia demandó el incumplimiento de las aportaciones anuales de tres millones de dólares de Barrick al Fondo de Compensación Ambiental, luego de la suspensión temporal del proyecto. Barrick había comprometido en 2005, en el marco del Protocolo de Compensación Ambiental, un pago de 60 millones en 20 años. Finalmente, se llegó a un acuerdo transaccional por el cual Barrick se obligó a pagar aproximadamente 20 millones.

89. B. SCHORR. N. 25.

90. Véase $<$ https://bit.ly/3mO5kXx $>(06 / 07 / 2021)$ y $<$ https://bit.ly/3FE5gCl $>(06 / 07 / 2021)$.

91. Por ejemplo, Antofagasta Minerals es parte del consorcio Tethyan Copper, demandante en el arbitraje contra la República de Pakistán ya citado. 
Ahora bien, tras protestas ciudadanas y una serie de graves actos de violencia acontecidos en el país a partir del mes de octubre de 2019, la ciudadanía aprobó el inicio de un proceso constituyente, con el fin de elaborar una nueva Constitución. El texto constitucional será elaborado por una Convención electa democráticamente en mayo de 2021 y se someterá a un plebiscito de aprobación o rechazo en 2022.

Como es evidente, el proceso constituyente en curso introduce un elemento de incertidumbre en el ámbito de los derechos mineros en Chile, garantizados en las últimas décadas a nivel constitucional y orgánico constitucional, según se vio ${ }^{92}$.

La propia regulación del proceso de elaboración de la nueva Carta Fundamental deja a salvo los tratados internacionales ratificados y que se encuentren vigentes ${ }^{93}$. Con todo, el Estado chileno deberá manejar con especial cuidado la nueva normativa constitucional y su posterior implementación, considerando que existen múltiples grupos de interés buscando una participación estatal aún mayor en la explotación de recursos naturales, y particularmente en el manejo del recurso hídrico, indispensable en los proyectos mineros. Asimismo, el movimiento a favor de la nueva Constitución ha estado marcado por grupos indigenistas ${ }^{94}$.

Un descuido por parte de las autoridades chilenas podría configurar casos de infracción al Trato Justo y Equitativo y otros estándares propios del derecho internacional de inversiones, ya puestos a prueba en materia minera a nivel regional.

\subsection{Un contraste con América Latina}

¿Qué explica que en Chile no exista el mismonivel de litigiosidad minera internacional que en el resto de América Latina? Por cierto, la actividad presenta los mismos riesgos conceptuales que en el resto del mundo. Los problemas que genera la industria en las cercanías de sus instalaciones son los mismos, y el país mantiene vigentes

92. El proceso no es nuevo en la región. Ya han existido Asambleas Constituyentes en Honduras (1982), Colombia (1991), Venezuela (1999), Ecuador (2008) y Bolivia (2009).

93. Constitución Política de Chile, Artículo 135.

94. Las reglas de la Convención Constitucional aseguraron 17 escaños reservados para representantes de pueblos originarios, de un total de 155 convencionales. 
una serie de normas tendientes a proteger el medioambiente y los derechos de las comunidades locales, con especial énfasis en las comunidades indígenas. Como queda de manifiesto en el caso Pascua Lama, las comunidades afectadas pueden ser igual de conflictivas que en otros países de la región.

Por su parte, en Chile se presentan las materias y discusiones propias de la lex mineralia, como por ejemplo de qué manera cuantificar la paralización de un proyecto minero o bien la forma de calcular los royalties o comisiones aplicables ${ }^{95}$. En tal sentido, los distintos grupos mineros mantienen y negocian toda clase de estrategias de estabilización de las reglas del juego.

Por lo demás, hemos visto que la institucionalidad para canalizar la solución de disputas por vía arbitral está preparada. De igual forma, existen múltiples expertos en minería, abogados con conocimiento de la normativa sectorial y peritos con amplia experiencia en el sector. Con todo, salta a la vista como nota distintiva la importante participación empresarial directa del Estado en la explotación del cobre, por lejos el mineral más importante en el país.

Asimismo, el riesgo de que surjan conflictos de inversión minera por denegación de permisos está fuertemente mitigado en la medida que son los tribunales, y no los funcionarios de la administración de turno, los encargados de constituir y extinguir las concesiones mineras, todo lo cual reduce la arbitrariedad.

Por último, la industria ha probado ser seria y está tan desarrollada que sus intervinientes parecieran apostar siempre al largo plazo. Obviamente, ello reduce la conflictividad y obliga a redoblar esfuerzos para alcanzar acuerdos transaccionales. Lo anterior se aprecia de manera transversal en distintas disputas aquí revisadas, desde el acuerdo CODELCO-Anglo American hasta las controversias del litio $^{96}$.

95. En paralelo al proceso constituyente, se encuentra actualmente en tramitación un ambicioso proyecto de ley que busca establecer un nuevo royalty a la minería en Chile. Al respecto, nótese que durante el segundo trimestre de 2021 el cobre alcanzó su máximo peak histórico, transándose en 4,26 dólares la libra.

96. Lo mismo resulta de la propia experiencia de este autor. En efecto, incontables controversias vinculadas al ámbito minero son transadas regularmente, con miras al desarrollo de uno o más proyectos futuros. 


\section{Conclusiones}

El arbitraje de minería empieza a configurar a nivel global un ámbito de práctica especializada, que atiende a los riesgos y peculiaridades de este sector. Las controversias mineras pueden ser adecuadamente canalizadas a través del sistema arbitral, gracias a la especialidad, dedicación, rapidez y neutralidad del tribunal, sumadas a la revisión restringida del laudo y otros beneficios propios del arbitraje como método de solución de disputas.

A nivel latinoamericano, los conflictos sociales y ambientales han constituido la fuente principal de disputas transfronterizas, destacando los conflictos entre inversionistas extranjeros y Estados receptores de capitales.

En el caso de Chile, importantes disputas mineras han sido resueltas a nivel doméstico, ya sea ante tribunales estatales o mediante arbitrajes locales. A pesar de la relevancia de la industria en el país, a la fecha no han existido grandes arbitrajes internacionales mineros más allá de los referidos en este artículo. Si bien la actividad presenta los mismos riesgos que en el resto de la región, la importante participación directa del Estado en la explotación del recurso minero y la sólida normativa a favor de los particulares tiende a diluir la conflictividad, apreciándose una tendencia a favor de la transacción de las disputas.

No obstante, tanto el marco normativo vigente como la disponibilidad de expertos en la materia para actuar como árbitros y peritos permiten afirmar que la vía arbitral es conveniente para resolver las controversias del sector. Si a lo anterior sumamos la presencia significativa de capitales extranjeros, las tendencias de la región latinoamericana en el ámbito de los conflictos mineros y el proceso constituyente actualmente en curso en el país, se aprecia que están dadas las condiciones para canalizar las disputas mineras que surjan en lo sucesivo por la vía del arbitraje internacional comercial y de inversiones. 

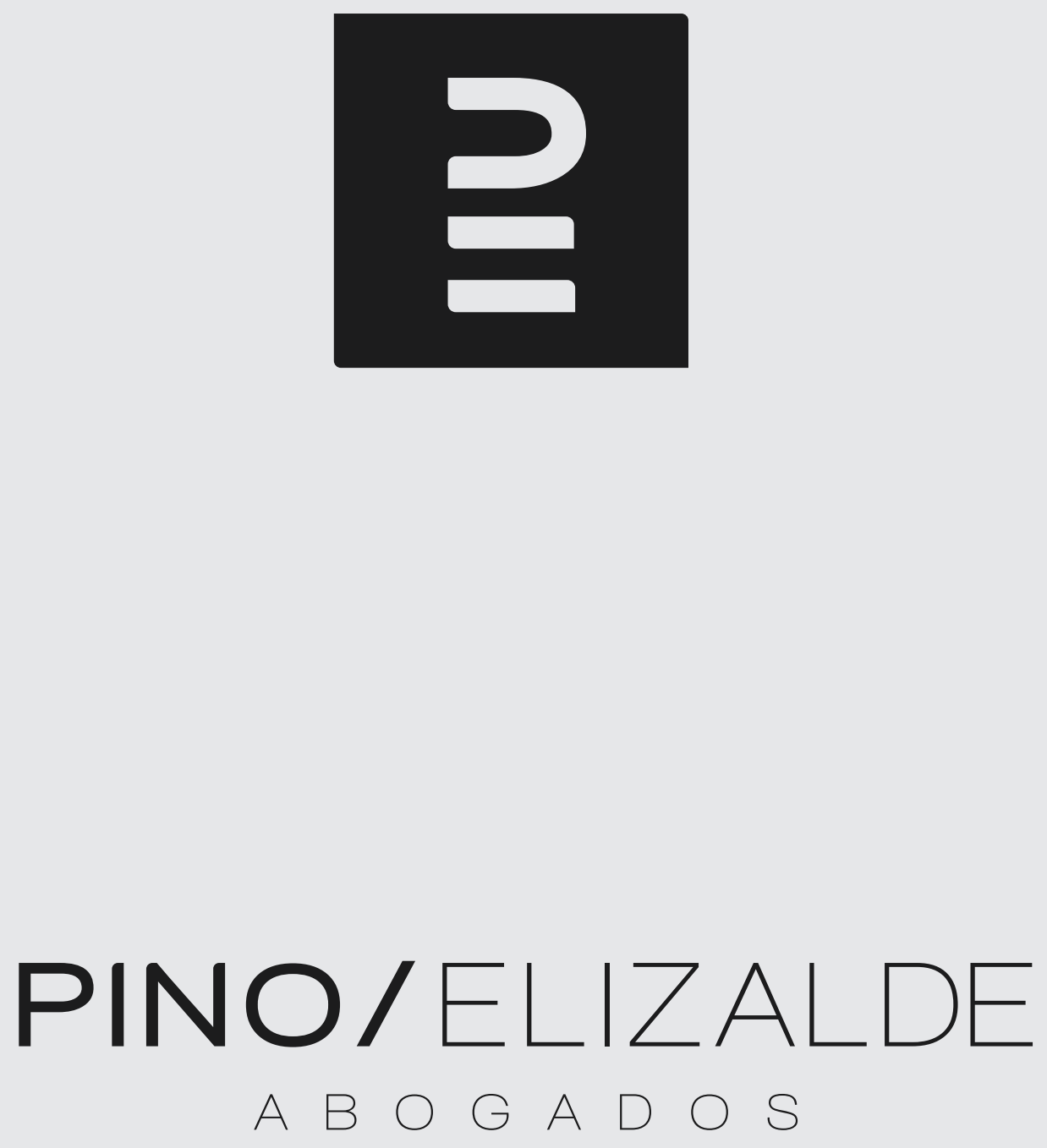

ww w.pinoelizalde.com 
